produkt ist vegan, halal und koscher und für eine natürliche PAR-Therapie ohne Chlorhexidin geeignet. Es wird abends aufgetragen und wirkt bis zu zwölf Stunden wachstumshemmend auf anaerobe Bakterien!“

Mit einem frischen Rasenduft in der Nase gehen wir zum Nebenstand, zu einer noch älteren Dentalfirma - auch hier ist bereits alles für uns angerichtet.

\section{Gang: Neue Implantat-Linie mit Geschichte}

Unter dem Motto „Back to the roots - shaping the future“ präsentiert Hager \& Meisinger (1888 gegründet) mit My Plant II erstmals eine Implantat-Linie. Sie wurde mit Prof. Dr. Georg-Hubertus Nentwig und Dr.-Ing. Walter Moser entwickelt und basiert somit auf einer fast 30-jährigen klinischen Erfahrung. „Wir haben uns zusammengetan, um die Stärken des bewährten Systems zu stärken und Schwächen zu verbessern. Herausgekommen ist ein zweiteiliges Titanimplantat mit hoher Primärstabilität, einer mikrobewegungsfreien Implantat-Abutment-Verbindung und tiefem Platform Switching “, erläutert Daniel Mundus, Pressesprecher, und fügt hinzu: „Wir sind uns der Qualität so sicher, dass wir eine lebenslange Garantie darauf geben!“

Wir verlassen das Traditionsunternehmen und folgen dem Mann mit Warnweste und Schild, vorbei an großen Kartons mit Süßigkeiten und Gebäck (der zuckrigen Wochenration für Standpersonal und -besucher). Wir werden erneut durch einen Müllcontainer aufgehalten, sicher umgeleitet und stehen kurze

\title{
„Meine Zähne sind wie Duisburg und Gelsenkirchen"
}

\begin{abstract}
Als Fernsehmoderatorin nimmt Barbara Schöneberger kein Blatt vor den Mund; sie lacht gerne und viel und hat immer einen flotten Spruch auf den Lippen. Davon konnten wir uns auch auf der IDS überzeugen. Wir sprachen mit der quirligen Markenbotschafterin von Oral-B direkt am Messestand.
\end{abstract}

DFZ: Frau Schöneberger, Sie sind für viele eine Traumfrau. Wie sollte Ihr Traumzahnarzt sein?

Barbara Schöneberger: Ich habe zum Glück kein Zahnarzttrauma; ich bin da ganz entspannt. Ich mache den Mund auf, mein Zahnarzt macht, was er tun muss, und ich mache den Mund wieder zu - fertig! Mehr brauche ich nicht.

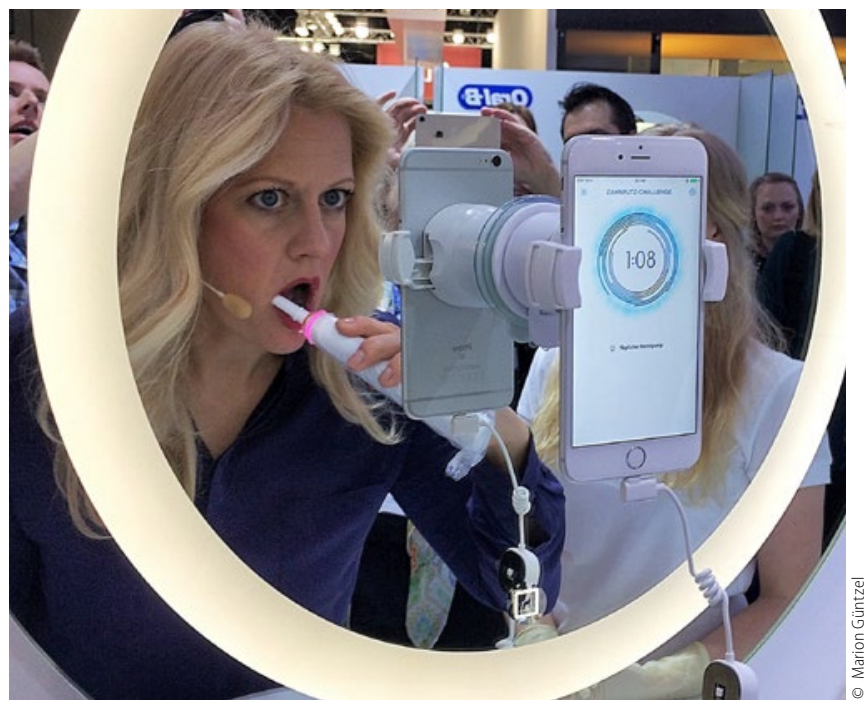

Frau Schöneberger bei der Arbeit: putzmunter und voll konzentriert.
DFZ: Sind Sie neugierig? Möchten Sie wissen, was er genau tut? Schöneberger: Ehrlich? Lieber nicht! Je schneller ich aus dem Behandlungsstuhl und der Praxis wieder raus bin, desto besser.

\section{DFZ: Sie sind sehr diszipliniert - auch bei der Zahnpflege?}

Schöneberger: Ja, einmal am Tag reicht - nein, Quatsch! Auch beim Zähneputzen bin ich gründlich. Manchmal habe ich aber Probleme, denn meine Zähne sind wie Duisburg und Gelsenkirchen - da ist immer noch Essen dazwischen (lacht). Gut nicht? Den Witz habe ich mir extra für die Dentalmesse aufgehoben.

\section{DFZ: Putzen Sie Ihre Zähne vor wichtigen Terminen?}

Schöneberger: Nein, vor Auftritten oder Interviews putze ich nicht noch mal extra. Ich strecke kurz vorher meinem Stylisten die Zähne entgegen, und er schaut, ob noch Mohnkügelchen dazwischen sind - das war's! Aber das ist gar keine schlechte Idee. Vielleicht wird mein Auftritt dann noch strahlender... (grinst breit).

DFZ: Wie bringen Sie Ihren Kindern bei, dass Mundhygiene wichtig ist? Schöneberger: Ich habe meinem Sohn, als er etwa vier Jahre alt war, ein Internet-Video gezeigt, wo sich viele hässliche Bakterien im Mund tummelten. Die Wirkung war nachhaltig: Er putzt nach wie vor ganz brav seine Zähne!

\section{DFZ: Und wie wichtig ist Ihnen Ihr Zahnfleisch?}

Schöneberger: Äh, da hängen die Zähne dran bzw. drin, nicht? Schauen Sie doch mal (hebt ihre Oberlippe hoch); schaut super aus, oder?

DFZ: Frauen im Rampenlicht lassen gerne mal etwas an Ihrem Körper machen. Ist bei Ihnen noch alles echt im Mund?

Schöneberger: Ich habe zum Glück ein recht zahngesundes Gebiss. Als Kind bin ich im Schwimmbad mal hingefallen, das haben nicht alle Teile meiner Schneidezähne überlebt, aber ansonsten ist hier alles echt (klopft sich an die Zähne). 